\title{
$\mathrm{EMR}$ 의 자발적 약물부작용보고 시스템을 이용한 한약약물유해반응 분석
}

\author{
김미경 ${ }^{1}$ 한창호 ${ }^{1,2}$ \\ ${ }^{1}$ 동국대학교 한의학연구소, ${ }^{2}$ 동국대학교 한의과대학 내과학교실
}

\section{Analysis of Herbal-drug-associated Adverse Drug Reactions Using Data from Spontaneous Reporting System in Electronic Medical Records}

\author{
Mikyung Kim ${ }^{1}$, Chang-ho Han ${ }^{1,2}$ \\ ${ }^{1}$ Research Institute of Oriental Medicine, Dongguk University \\ ${ }^{2}$ Dept. of Internal Medicine, College of Korean Medicine, Dongguk University
}

\begin{abstract}
Objectives: The purpose of this study was to understand the status of reporting and characteristics of adverse drug reactions (ADRs) induced by herbal drugs and to make a suggestion for the domestic pharmacovigilance system on herbal medicine.

Methods: We carried out a hospital-based observational study at Dongguk University Ilsan Oriental Hospital from April 2012 to December 2014. We reviewed all the herbal-drug-associated ADRs reports registered to the spontaneous ADR reporting system in electronic medical records of the hospital in the period.

Results: We found out 101 reports including 163 herbal-drug-associated ADRs from 97 patients. Females (69.3\%) outnumbered males and the most frequent age group was the $50 \mathrm{~s}(44,27.0 \%)$. No serious adverse event was observed. The most commonly reported ADR was gastro-intestinal system disorders $(68,41.5 \%)$ followed by skin-related disorders $(42,25.8 \%)$. Diarrhea $(29,17.8 \%)$ was the most frequently referred clinical manifestation. Most ADRs were induced by internal medicines $(160,98.2 \%)$ including manufactured $(36,22.1 \%)$ and self-prepared decoction $(160$, $76.1 \%$ ). The pairs of Igi-hwan-diarrhea, gamiboa-tang-vomiting, and Magnoliae Flos-gastro-intestinal-system-related ADRs were observed twice each and the others appeared only once.

Conclusions: We propose Korean government to take an initiative in national pharmacovigilance system for herbal medicine. To perform the surveillance on herbal drugs, the Association of Korean Medicine (AKOM) should set up a nationwide network by designating centers connecting the Korean medical hospitals, local Korean medicine clinics, and the public health centers. The government and AKOM should also educate and encourage them to understand the pharmacovigilance system and report the ADRs actively.
\end{abstract}

Key Words : side effects, adverse drug reaction, ADR reporting system, herbal-drug-associated ADR, pharmacovigilance, herbal medicine, Korean medicine

\section{서 론 \\ 한약은 자연에서 유래한 것이므로 안전할 것이라 는 막연한 경험적 믿음에 의문을 제기하는 연구결과}

와 언론보도가 이어지면서 한약의 안전성에 대한 사 회적 관심이 고조되고 있다 ${ }^{1,2)}$. 유럽에서 비만 치료 제로 시판되었던 중약(中藥)중 광방기의 aristolochic acid가 포함되어 신장독성을 일으킨다는 보고 이후

\footnotetext{
- Received: 19 March 2015 -Revised: 25 March 2015

- Accepted : 25 March 2015

- Correspondence to : 한창호(Chang-ho Han)

780-714 경상북도 경주시 동대로 123 동국대학교 한의과대학 내과학교실

Tel : +82-54-770-1257, FAX : +82-54-770-1500, E-mail : hani@dongguk.ac.kr
} 
한약의 안전성에 대한 논란이 있었으며 ${ }^{3)}$, 미국에서 는 심뇌혈관계 관련 부작용을 이유로 마황 등 ephedra alkaloid를 함유하는 한약재가 포함된 기능 성식품에 대해 시판이 중지된바 있다 ${ }^{4)}$. 일본에서는 소시호탕에 의한 폐렴 발생 사례가 보고되기도 했고 5) 국내에서는 약인성 간손상으로 입원한 371 례에 대한 조사 결과, 간손상의 원인이 한약으로 확인된 경우가 $27.5 \%$ 로 가장 많았다는 보고도 있었다 ${ }^{6}$. 국 내외적으로 한약의 안전성 관련 연구들이 지속되고 있지만 이들은 사례보고, 임상연구, 문헌연구가 주 를 이루고 있는 실정이다 ${ }^{7,8)}$. 소비자들의 의구심과 사회적으로 고조된 불안감을 없애기 위해서는 좀더 체계적이고 구체적인 한약의 안전성에 대한 근거를 구축할 필요가 있다.

약물감시(Pharmacovigilance)란 약물유해반응(Adverse Drug Reaction, ADR)을 탐지 평가 해석하여 약화 사고를 예방하기 위한 과학적 연구 및 활동을 말하 며9), 약물유해반응의 조기발견 및 효과적 예방을 위 한 약물감시제도의 대표적 수단 중 하나가 자발적부 작용신고제도이다 ${ }^{10)}$. 우리나라의 경우, 1988 년부터 자발적부작용보고제도를 시행하고 있으며, 제약회 사와 약사의 경우 약물 시판 후 발생한 부작용 보고 를 의무화하고 있다. 약물감시 선진국들도 의사에게 부작용보고를 강제하고 있지는 않으며, 의료인과 환 자 및 일반인들의 자발적 부작용 보고를 독려하고 있다 ${ }^{9}{ }^{10)}$. 우리나라에서는 2008년 이후 자발적 부작 용보고를 체계화하기 위하여 당시 식품의약품안전 청 산하에 연구사업으로 지역약물감시센터를 두고 적극적으로 약물유해반응을 수집하여 성과를 거둔 바 있다. 현재는 조직이 확대된 식품의약품안전처 (이하 식약처)에 신고된 부작용을 수집 검토 평가하 기 위해 한국의약품안전관리원을 설치하였으며, 산 하에 전국 25 개 병원에 지역의약품안전센터를 두고, 2 개의 중앙의약품안전센터를 지정하여 관리하고 있 다. 국립중앙의료원과 대한약사회는 중앙의약품안 전센터로 지정되어 지역의약품안전센터와 더불어 약물유해반응을 취합하여 관련 자료를 보고하고 있 으며, 식약처 뿐 아니라 세계보건기구(WHO)의 웁
살라모니터링센터(Uppsala Monitoring Center, 이하 WHO-UMC)에도 제출함으로써 약물유해반응의 국 제적 연구와 관리에 기여하고 있다 ${ }^{9)}$.

동국대학교 일산한방병원은 2008년 지역의약품 안전센터로 지정된 동국대학교 일산병원과 동일한 전자의무기록(Electronic Medical Records, EMR) 환 경이 구축되어 있으며 $\mathrm{EMR}$ 에 연계된 자발적 약물 부작용보고 시스템 또한 공유하고 있어 같은 시스템 을 통해 한약을 포함한 약물부작용을 보고하고 있 다. 이 시스템이 가동된 이후 약 4년간 축적된 사례 중 한약에 의한 약물부작용을 모아 권 등11) 이 보고 한 바 있으나, 수집된 부작용 보고사례가 많지 않고, 한약 및 여타 약물과의 인과성평가의 어려움으로 한 약약물유해반응의 현황을 정확히 파악하기에는 어 려움이 있었다.

이후 저자들은 실제로 약물감시사업의 인과성평 가 업무를 수행하는 과정에서 선행 연구때 보고된 사례 이외에 지속적으로 좀더 많은 수의 한약약물유 해반응 사례를 확보할 수 있었다. 또한 이들을 평가 분석하는 과정에서 평가자간의 인과성평가의 차이 가 있음을 확인하고 차이점을 분석하였으며, 시스템 상 부정확한 정보를 확인하여 수정하는 과정을 통하 여 양질의 한약약물유해반응 자료를 확보하고 분석 할 수 있었는바 그 결과를 보고하고, 이를 바탕으로 한약의 약물감시제도에 대해 제안하고자 한다.

\section{연구대상과 방법}

이 연구는 동국대학교 일산한방병원 기관윤리심 의위원회(Institute Review Board, IRB)의 승인을 받 은 연구계획서에 따라 진행되었다.

\section{1. 연구대상}

2012년 4월부터 2014년 12월까지 33개월간 원내 $\mathrm{EMR}$ 의 자발적 약물부작용보고 시스템을 통해 보고 된 부작용 사례 중 의심약물이 동국대학교 일산한방 병원(입원, 외래, 응급실)에서 처방한 한약인 경우를 선별하여 분석하였다. 


\section{2. 연구방법}

\section{1) 보고서 재검토}

시스템의 부작용사례보고서에는 최초보고자가 간 단히 입력한 내용과 지역의약품안전센터(이하 센터) 평가진이 최초 보고서와 EMR 검토를 통해 추가 입 력한 내용이 포함되어 있다. 한의사인 연구자들은 최초 보고자와 원내 센터 평가진이 보고서에 입력한 모든 내용을 신중히 검토하고, EMR에서 관련 내용 을 추가로 확인하여, 의심약물과 유해사례관련 내용 을 추가하고 부정확한 정보는 수정하였다.

\section{2) 의심약물-유해사례 조합 생성}

연구자들은 위에서 재검토한 보고서에 의거하여 의심약물과 유해사례의 조합을 생성하였다. 즉, 하 나의 보고서에 한 개 이상의 의심약물 혹은 한 개 이상의 유해사례가 포함되어 있는 경우 이를 분리하 여 하나의 의심약물에 하나의 유해사례씩 짝지은 조 합을 생성하고 이를 한 건의 사례로 간주하였다. 예 를 들어 1 건의 보고서에 의심약물로 $\mathrm{A}$ 와 $\mathrm{B}$ 가 지목 되고, $\mathrm{C}$ 와 $\mathrm{D}$ 의 유해사례가 입력되어 있으면, $\mathrm{A}-\mathrm{C} /$ $\mathrm{A}-\mathrm{D} / \mathrm{B}-\mathrm{C} / \mathrm{B}-\mathrm{D}$ 총 네 건의 조합이 생성된다.

\section{3) 인과성 평가}

의심약물과 유해사례간의 인과관계를 평가하기 위해 1 차적으로 $\mathrm{WHO}-\mathrm{UMC}$ 인과성평가 지표(이하 $\mathrm{UMC}$ 지표)를 사용하였다(Appendix I). UMC 지표 는 시간적 선후관계, 투여중단 혹은 재투약 정보, 병 용약물이나 수반질환 등 다른 원인에 의한 설명 가 능성 여부를 기준으로, 약물과 유해사례 간의 인과 관계를 확실함(certain), 상당히 확실함(probable/ likely), 가능함(possible), 가능성 적음(unlikely), 평 가곤란(conditional/unclassified), 혹은 평가불가 (unassessible/unclassifiable)로 분류한다 ${ }^{12)}$. 연구자들 은 센터 평가진이 이미 $\mathrm{UMC}$ 자료를 사용하여 평가 완료했거나 혹은 평가하지 못하고 남겨둔 사례를 포 함한 모든 사례에 대해 같은 지표로 인과성 평가를 재 시행하였고, 센터 평가진의 평가 결과와 비교하였다.

또한 2차 평가 도구로 약물유해반응 인과성평가
Appendix I. WHO-UMC Causality Categories. ${ }^{2)}$

\section{1. 확실함(certain)}

의약품 등의 투여·사용과의 전후관계가 타당하고 다른 의약품 이나 화학물질 또는 수반하는 질환으로 설명되지 아니하며, 그 의약품등의 투여중단시 임상적으로 타당한 반응을 보이고, 필요에 따른 그 의약품등의 재투여시, 약물학적 또는 현상학 적으로 결정적인 경우

\section{2. 상당히 확실함(probable/likely)}

의약품등의 투여·사용과의 시간적 관계가 합당하고 다른 의약 품이나 화학물질 또는 수반하는 질환에 따른 것으로 보이지 아 니하며, 그 의약품등의 투여중단시 임상적으로 합당한 반응을 보이는 경우(재투여 정보 없음)

3. 가능함(possible)

의약품등의 투여·사용과의 시간적 관계가 합당하나 다른 의약 품이나 화학물질 또는 수반하는

질환에 따른 것으로도 설명되며, 그 의약품등의 투여중단에 관한 정보가 부족하거나 불명확한 경우

\section{4. 가능성 적음(unlikely)}

의약품등의 투여·사용과 인과관계가 있을 것 같지 않은 일시 적 사례이고, 다른 의약품이나 화학물질 또는 잠재된 질환에 따른 것으로도 타당한 설명이 가능한 경우

5. 평가 곤란(conditional/unclassified) 적정한 평가를 위해 더 많은 자료가 필요하거나 추가 자료를 검토중인 경우

6. 평가 불가(unassessible/unclassifiable) 정보가 불충분하거나 상충되어 판단할 수 없고 이를 보완하거 나 확인할 수 없는 경우

를 위한 한국형알고리즘 버전 2.0(이하 KA)을 적용 하여 인과성 평가를 추가 시행하였다(Appendix II). $\mathrm{KA}$ 는 시간적 선후관계, 감량 또는 중단반응, 유해 사례의 과거력, 병용약물의 효과, 비약물요인의 영 향, 허가사항 반영여부(기존에 알려진 지식), 재투여 반응, 검사결과의 8 개 항목에 대해 점수를 매기고 합산 결과를 기준으로 인과성을 평가하는 점수형 알 고리즘이다. 각 항목마다 인과관계를 높이는 근거가 존재할 경우, 정해진 기준에 따라 최소 1점에서 3점, 반대로 낮출 경우 역시 경우에 따라 -1점에서 -3점 을 주고, 정보가 없거나 필요한 활동을 수행하지 않 아 판단할 수 없을 경우 0 점을 부여한 뒤, 최종 합산 점수가 12점 이상이면 확실함(certain), 6-11점은 가 능성 높음(probable), 2-5점은 가능성 있음(possible), 1점 이하는 가능성 낮음(unlikely)으로 분류한다 ${ }^{12}$. 허가사항 반영여부(기존에 알려진 지식)를 확인하기 
위해 드러그인포(http://www.druginfo.co.kr), 한국한 의학연구원 전통의학정보포털의 한약처방검색 데이 터베이스(http://oasis.kiom.re.kr/pres/prbaseSearch. jsp), 전국한의과대학 본초학교과서 ${ }^{13)}$, WHO Monographs on Selected Medicinal Plants ${ }^{14)}$, 한약재 안전 및 품 질관리 규정(식품의약품안전처 고시 제2013-7호, 제 2장 규격품 관리 제7조 용기 또는 포장의 기재사항 의 별표 1. 독성주의한약재 21 개 품목)을 참고하였 다.

\section{3. 평가방법}

\section{1) 약물유해반응 선별}

연구자들은 $\mathrm{UMC}$ 지표를 적용하여 possible, probable/likely, certain으로 판정된 경우 의심약물과 유해사례 간의 인과관계를 배제할 수 없으므로 이러 한 사례들을 선별하여 약물유해반응으로 간주하였다.

\section{2) 인구학적 특성}

약물유해반응이 발생한 환자들의 성별과 연령 분 포를 확인하고, 전체 집단 및 남녀별 평균 연령과

Appendix II. Korean Algorithm for ADR Causality Assessment (version 2.0). ${ }^{12)}$

\begin{tabular}{|c|c|}
\hline 시간적 선후관계 & $\begin{array}{l}\text { 약물 투여와 유해사례 발현의 선후관계에 관한 정보가 있는가? } \\
\text { 선후관계 합당(+3) } \\
\text { 선후관계 모순(-3) } \\
\text { 정보없음 }(0)\end{array}$ \\
\hline 감량 또는 중단 & $\begin{array}{l}\text { 감량 또는 중단에 대한 정보가 있는가? } \\
\text { 감량 또는 중단 후 임상적 호전이 관찰됨 }(+3) \\
\text { 감량 또는 중단과 무관한 임상경과를 보임(-2) } \\
\text { 감량 또는 중단을 시행하지 않음 }(0) \\
\text { 정보없음(0) }\end{array}$ \\
\hline 유해사례의 과거력 & $\begin{array}{l}\text { 이전에 동일한 또는 유사한 약물로 유해사례를 경험한 적이 있는가? } \\
\text { 예 }(+1) \text { 아니오(-1) } \\
\text { 정보없음 }(0)\end{array}$ \\
\hline 병용약물 & $\begin{array}{l}\text { 병용약물에 대한 정보가 있는가? } \\
\text { 병용약물 단독으로 유해사례를 설명할 수 없는 경우 }(+2) \\
\text { 병용약물 단독으로 유해사례를 설명할 수 있는 경우 }(-3) \\
\text { 의심약물과 상호작용으로 설명되는 경우(+2) } \\
\text { 병용약물에 대한 설명이 없는 경우(0) } \\
\text { 정보없음 }(0)\end{array}$ \\
\hline 비약물요인 & $\begin{array}{l}\text { 비약물요인에 대한 정보가 있는가? } \\
\text { 비약물요인으로 유해사례가 설명되지 않음 }(+1) \\
\text { 비약물요인으로 유해사례가 설명됨(-1) } \\
\text { 정보없음(0) }\end{array}$ \\
\hline 약물에 대해 알려진 정보 & $\begin{array}{l}\text { 허가사항(label, insert 등)에 반영되어 있음 }(+3) \\
\text { 허가사항에 반영되어 있지 않으나 증례보고가 있었음 }(+2) \\
\text { 알려진 바 없음 }(0)\end{array}$ \\
\hline 재투약 & $\begin{array}{l}\text { 약물 재투여에 관한 정보가 있는가? } \\
\text { 재투약으로 동일한 유해사례가 발생함 }(+3) \\
\text { 재투약으로 동일한 유해사례가 발생하지 않음 }(-2) \\
\text { 재투약하지 않음 }(0) \\
\text { 정보없음 }(0)\end{array}$ \\
\hline 특이적인 검사 & $\begin{array}{l}\text { 유발검사, 약물농도 검사와 같은 특이적인 검사를 시행하였는가? } \\
\text { 양성 }(+3) \text { 음성 }(-1) \\
\text { 결과를 알 수 없음 }(0) \text { 정보없음 }(0)\end{array}$ \\
\hline
\end{tabular}

최고점수 : 19점, 최하 점수 : -13점. 최종 합산 점수가 12점 이상이면 확실함(certain), 6-11점은 가능성 높음(probable), 2-5점은 가능성 있음(possible), 1 점 이하는 가능성 낮음(unlikely)으로 분류한다. 
표준편차를 구하였다.

\section{3) 중증도}

약물유해반응의 중증도 평가를 위해 식약처의 중 증도 기준과 LDS scale을 사용하였다. 식약처의 중 증도 기준은 약물유해반응이 일상 생활 수행 능력에 미치는 영향 등을 근거로 약물유해반응을 경증 (mild), 중등증(moderate), 중증(severe)으로 구분한 다(Appendix III) ${ }^{12)}$.

Appendix III. Severity of Adverse Drug Reactions. ${ }^{12)}$

\section{1. 중증(severe)}

증상이 일이나 일상의 활동을 수행할 수 없을 만큼 불편감을 야기하며, 의심약물을 중단할 만큼

불편감이 있다. 증상을 경감하기 위한 치료가 필요하다.

\section{2. 중등증(moderate)}

증상이 일상의 활동을 방해할 만큼 불편하다. 행동에 영향을 미침, 증상을 경감하기 위한 치료가

필요할 수 있다.

\section{3. 경증(mild)}

증상 또는 징후를 자각할 수 있으나 불편감을 주지 않고 참을 수 있으며, 행동이나 기능에 영향을 미치지 않는다. 증상을 경 감하기 위한 치료가 필요하지 않다.

LDS scale은 삶의 질 저하, 투약 중단후 반응, 추 가적 처치의 필요성, 치료기간의 연장 또는 입원 치 료의 필요성, 일시적 혹은 영구적 기능이상 발생 여 부, 업무수행능력의 영구소실 여부, 약물유해반응의 위험성 등 10 가지 항목에 대해 항목당 최대 3 점에서
-1점을 부여하여 총점이 9점 이상이면 중증(severe), 5-8점이면 중등증(moderate), 4점 이하이면 경증 (mild)으로 평가한다(Appendix IV) ${ }^{15,16)}$.

\section{4) 약물유해반응의 종류}

$\mathrm{WHO}-\mathrm{UMC}$ 에서 개발한 약물유해사례 코드 체계 인 WHO-Adverse Reaction Terminology (WHO-ART) 092 버전을 기준으로 약물유해반응을 분류하였다. WHO-ART는 신체기관계분류(System-Organ Classes, SOC), 상위용어(High Level Terms, HLT), 우선순위 용어(Preferred Terms, PT), 하위포함용어(Included Terms, IT)의 4단계로 구성되어 있다 ${ }^{17)}$. 이 연구에 서는 신고된 약물유해반응의 종류를 WHO-ART의 $\mathrm{PT}$ 에 따라 구분하고, 각 $\mathrm{PT}$ 의 소속 $\mathrm{SOC}$ 에 따른 발 생 빈도를 분석하였다.

\section{5) 약물병용상황}

보고서 및 원내 EMR을 통해 약물유해반응 발생 전후로 복용 중이던 약물을 추적하여 약물유해반응 발생 당시 의심약물 외에 다른 약물을 병용하고 있 었는지 조사하였다. 이때 약물 병용 상황은 의심약 물로 지목된 한약만을 단독으로 복용하고 있던 경우 와 기타 약물을 병용하고 있던 경우로 크게 구분하 였으며, 기타 약물을 병용한 경우는 병용 약물의 종 류에 따라 병용약물이 한약, 양약, 혹은 한약+양약 인 경우로 다시 구분하였다.

Appendix IV. LDS Scale Categories. ${ }^{15,}{ }^{16)}$

\begin{tabular}{llll}
\hline \multicolumn{1}{c}{ Question } & Yes & No & Unknown \\
\hline Did the adverse drug reaction impair the patient's quality of life? & 1 & -1 & 0 \\
\hline Was the (immediate) discontinuation of the drug necessary or recommended? & 1 & 0 & 0 \\
\hline Was the use of a different drug or other therapy necessary or recommended? & 1 & 0 & 0 \\
\hline Did the adverse drug reaction prolong treatment or lead to hospitalization? & 1 & 0 & 0 \\
\hline Did the adverse drug reaction cause temporary malfunctioning of an organ (system)? & 1 & 0 & 0 \\
\hline Did the adverse drug reaction cause permanent malfunctioning of an organ (system)? & 2 & 0 & 0 \\
\hline Did the adverse drug reaction lead to permanent inability to work? & 1 & 0 & 0 \\
\hline Was the adverse drug reaction potentially dangerous? & 1 & 0 & 0 \\
\hline Was the adverse drug reaction (potentially) life-threatening? & 2 & 0 & 0 \\
\hline Was the adverse drug reaction fatal? & 3 & 0 & 0 \\
\hline
\end{tabular}

The severity of the ADRs is classified according to the total score. A score of 1-4 indicates a mild reaction, a score of 5-8 a moderate reaction, and a score of $\geq 9$ a severe adverse drug reaction 


\section{6) 의심약물의 종류}

의심약물로 지목된 한약을 크게 외용약과 내복약 으로 구분하였다. 내복약은 다시 제제와 탕제로 나 누고, 각각의 약물은 포장 단위 별로 평가하였다. 제 제에는 보험엑스제, 기타 비보험 시판 제제 외에도 원내에서 조제한 환산제가 포함되었다. 제제의 제조 사나 규격, 구성 한약재 혹은 구성 성분의 종류 및 함량은 고려하지 않았다. 예를 들어 $\mathrm{A}$ 사의 우황청 심원과 $\mathrm{B}$ 사의 우황청심원, 그리고 원내 조제 우황청 심원은 구성 한약재 함량과 종류가 다르더라도 모두 ‘우황청심원'으로 포장되어 있으므로 같은 약물로 간주하였다. 약물의 명칭이 같더라도 탕제와 제제는 다른 약물로 구분하였다. 일례로 보험엑스제인 방풍 통성산과 탕제 방풍통성산은 처방명이 같더라도 다 른 약물로 간주하였다. 탕제는 탕제를 구성하는 개 별 한약재의 명칭이 같다면, 용량이 다르더라도 같 은 탕제로 간주하였다. 예를 들어 사군자탕의 경우, 사군자탕을 구성하는 개별 한약재인 인삼, 백출, 복 령, 감초가 포함되어 있기만 하면 개별 한약재의 사 용 용량이 다르더라도 모두 사군자탕으로 처리하였 다. 반면 처방전에 기재된 탕제의 명칭이 동일하더 라도 포함된 개별약재의 종류가 다르면 다른 탕제로 구분하였다. 일례로 처방명이 똑같이 사군자탕가감 방이라하더라도 사군자탕 원방에 진피가 들어간 탕 제와 사군자탕 원방에 반하가 들어간 탕제는 사군자 탕가감방 1 , 사군자탕가감방 2 와 같이 서로 다른 탕제 로 구분하여 재명명하였다. 약물유해사례 발생 전후 에 탕제의 구성 한약재 중 일부가 추가 제외되거나 용량이 바뀌어 탕제 전체가 아니라 개별 한약재를 의심약물로 지목할 수 있는 경우에도 1차적으로는 포장단위인 탕제를 의심약물로 간주하였다. 이후 2 차적으로 탕제 내 개별 한약재를 의심약물로 지목할 수 있는 경우를 따로 모아 분석하였다.

\section{결 과}

\section{1. 보고건수}

33 개월 동안 자발적 약물부작용보고 시스템에 신
고된 총 7,541건 중 원내에서 처방된 한약이 부작용 의심약물로 지목된 보고서는 101건이었다. 보고서 에 포함된 환자는 97명이었는데 이중 4명은 동일한 사람에서 2 건의 독립적 유해사례가 발생하여 한 사 람 당 2 건의 보고서가 제출되었고, 나머지는 모두 한 사람당 1 건의 보고서가 제출되었다. 의심약물이 처방된 당시 환자의 진료형태는 외래가 79 건 (78.2\%)으로 가장 많았고, 입원이 22건(21.8\%)이었 으며, 한방응급실에서 처방된 한약이 의심약물로 지 목된 경우는 한 건도 없었다. 보고자의 직능은 간호 사가 54건(53.5\%)으로 가장 많았고, 한약사가 42건 $(41.6 \%)$ 으로 그 뒤를 이었으며, 한의사와 의사는 각 4 건(4.0\%)과 1 건( $1.0 \%)$ 였다.

\section{2. 평가현황}

\section{1) 보고서 재검토}

101 건의 보고서를 검토하여 총 16 건에서 주요 내 용을 변경하였다. 이 중에는 의심약물을 수정한 보 고서가 13건, 유해사례를 수정한 경우 2건, 그리고 의심약물과 유해사례 항목 모두를 수정한 경우 1 건 이 포함된다. 의심약물 변경 사례는 3 가지 종류가 있었다. 이중에는 의무기록을 검토하고 약물 처방과 유해 사례 발생 시점의 선후관계를 고려하여 보고서 에 입력된 것과 다른 약물이 의심약물로 추정된 경 우 7건이 있었고, 여러 개의 한약재가 동시 투여되 는 탕제 처방명 대신 탕제 안에 포함된 특정 한약재 를 지목할 수 있었던 보고서가 6건, 단순 오기를 정 정한 보고서 1건이 포함되어 있다. 유해사례를 수정 한 사례는 3 건으로 유해사례를 추가한 사례가 2건 있었으며, 잘못 입력된 유해사례를 삭제한 경우가 1 건 있었다.

\section{2) 의심약물-유해사례 조합 생성}

1 개의 의심약물에 1 개의 유해사례를 조합하여 총 177 건의 사례를 생성하였다.

\section{3) 인과성 평가}

(1) 인과성평가결과(UMC 지표) 
Table 1. Between-group Comparison of the WHO-UMC Causality Assessment.

\begin{tabular}{ccccccc}
\hline Rater Group & Certain & Probable & Possible & Unlikely & Unclassified & Not done \\
\hline RPVC $^{*}$ & $0(0.0)$ & $6(3.4)$ & $97(54.8)$ & $1(0.6)$ & $2(1.1)$ & $71(40.1)$ \\
Authors $^{\dagger}$ & $0(0.0)$ & $17(9.6)$ & $146(82.5)$ & $14(7.9)$ & $0(0.0)$ & $0(0.0)$ \\
\hline
\end{tabular}

* Raters of Regional Pharmacovigilance Center in Dongguk University Ilsan Hospital, ${ }^{\dagger}$ Authors who are Korean Medical doctors

연구자들은 센터 평가진에서 인과관계를 판단하 지 못했거나(unclassified로 분류한 경우) 평가하지 않은 사례를 포함하여 시스템에 보고된 모든 사례에 $\mathrm{UMC}$ 지표를 적용하였고, 그 결과 총 177 건 모두를 probable, possible, 혹은 unlikely 중 하나로 분류할 수 있었다(Table 1). 센터 평가진에서 인과관계 평가 를 보류한 사례 73건을 제외한 104건 중 센터 평가 진과 연구자들의 평가 결과가 일치한 사례는 88 건 $(84.6 \%)$ 이었고, 불일치하는 사례는 16 건(15.4\%)이 었으며, 이중에는 센터 평가진이 probable로 분류한 것을 연구자가 possible로 바꾼 것이 2건, possible을 unlikely로 바꾼 것이 8건, possible을 probable로 바 꾼 것이 6 건이었다.

(2) 인과성평가결과 $(\mathrm{KA})$

전체 177 건에 대해 $\mathrm{KA}$ 총점을 기준으로 평가한 결과, 앞서 연구자들이 $\mathrm{UMC}$ 지표를 적용하여 평가 한 결과와 모두 일치하였다. $\mathrm{KA}$ 의 각 세부 항목에 대해 평가의 근거가 될 수 있는 정보를 확보하지 못 한 사례는 시간적 선후관계를 확인하기 어려운 사례 가 2건 있었으며, 감량 또는 중단반응을 확인하지

Table 2. Number of the Cases with No Available Information to Score Each Category of Korean Algorithm for ADR Causality Assessment version 2.0.

\begin{tabular}{cc}
\hline Categories & Number (\%) \\
\hline Chronologic relationship & $2(1.1)$ \\
Dose reduction or stop & $129(72.9)$ \\
Past history of ADR & $169(95.5)$ \\
Combined medication & $173(97.7)$ \\
Drug-unrelated cause & $118(66.7)$ \\
Any unveiled information of drugs & $173(97.7)$ \\
Re-challenge & $166(93.8)$ \\
Specific Tests & $177(100.0)$ \\
\hline
\end{tabular}

못한 사례가 129 건 있었고, 비약물요인의 영향을 배 제하기 어려운 사례가 118 건 등이었다(Table 2). 이 에 따르면 감량 또는 중단 반응에 대한 정보가 있는 경우는 48건(27.1\%), 재투약 반응 정보를 확보한 경 우는 11 건(6.2\%), 허가사항반영(기존에 알려진 지 식) 관련 정보가 존재하는 경우는 4 건(2.3\%)에 불과 하였으며, 시간적 선후관계로만 인과관계를 평가한 경우가 98건(55.4\%).이었다(Table 2)

\section{3. 약물유해반응의 특성}

\section{1) 약물유해반응 선별}

연구자가 $\mathrm{UMC}$ 지표를 기준으로 선별한 약물유 해반응은 총 163 건이었다.

\section{2) 인구학적 특성}

한약에 의한 약물유해반응을 경험한 환자는 남성 보다 여성(69.3\%)이 많았다(Table 3). 대상 환자의 연령 분포는 1 세에서 89 세 사이였으며, 남녀 모두 50 대의 빈도가 가장 높았고, 남성보다 여성의 평균 연령이 더 높았다(Table 3).

\section{3) 중증도 분석}

식약처의 중증도 기준을 적용한 결과, 약물유해반 응 163 건 중 159 건(97.5\%)이 경증(mild)이었고, 나 머지 4건(2.5\%)은 중등증(moderate)이었으며, 심각 한 유해사례는 없었다. LDS scale을 적용해도 동일 한 결과가 도출되었다.

\section{4) 약물유해반응의 종류(증상에 따른 분류)}

가장 많이 발생한 약물유해반응은 설사(29건, $17.8 \%$ )였으며, 소화불량(20건, $12.3 \%)$, 가려움증 $(17$ 건, $10.4 \%$ ), 발진(12건, $7.4 \%)$, 복통(10건, $6.1 \%)$ 과 
Table 3. Destribution of Adverse Drug Reactions by Gender and Age groups.

\begin{tabular}{cccc}
\hline & Total (\%) & Male $(\%)$ & Female $(\%)$ \\
\hline Number & $163(100.0)$ & $50(30.7)$ & $113(69.3)$ \\
Age & $49 \pm 20.8$ & $41 \pm 24.0$ & $52 \pm 18.3$ \\
$0-9$ & $10(6.1)$ & $8(4.9)$ & $2(1.2)$ \\
$10-19$ & $10(6.1)$ & $6(3.7)$ & $4(2.5)$ \\
$20-29$ & $8(4.9)$ & $3(1.8)$ & $5(3.1)$ \\
$30-39$ & $20(12.3)$ & $2(1.2)$ & $18(11.0)$ \\
$40-49$ & $20(12.3)$ & $8(4.9)$ & $12(7.4)$ \\
$50-59$ & $44(27.0)$ & $12(7.4)$ & $32(19.6)$ \\
$60-69$ & $30(18.4)$ & $7(4.3)$ & $23(14.1)$ \\
$70-79$ & $11(6.75)$ & $4(2.5)$ & $7(4.3)$ \\
$80+$ & $10(6.1)$ & $0(0.0)$ & $10(6.1)$ \\
\hline
\end{tabular}

Table 4. Types of Clinical Manifestations of Adverse Drug Reactions.

\begin{tabular}{|c|c|c|c|}
\hline Clinical Manifestations & Number & SOC* & Number $(\%)$ \\
\hline PRURITUS & 17 & Skin and appendages disorders & $42(25.8)$ \\
\hline RASH & 12 & & \\
\hline URTICARIA & 8 & & \\
\hline SWEATING INCREASED & 2 & & \\
\hline RASH FOLLICULAR & 2 & & \\
\hline ACNE & 1 & & \\
\hline MYALGIA & 1 & Musculo-skeletal system disorders & $1(0.6)$ \\
\hline DIZZINESS & 5 & Central \& peripheral nervous system disorders & $6(3.7)$ \\
\hline HYPERTONIA & 1 & & \\
\hline PALPITATION & 6 & Autonomic nervous system disorders & $6(3.7)$ \\
\hline INSOMNIA & 3 & Psychiatric disorders & $3(1.8)$ \\
\hline VOMITING & 5 & Gastro-intestinal system disorders & $68(41.5)$ \\
\hline DIARRHEA & 29 & & \\
\hline DYSPEPSIA & 20 & & \\
\hline ABDOMINAL PAIN & 10 & & \\
\hline NAUSEA & 2 & & \\
\hline FLATULENCE & 2 & & \\
\hline HEPATIC ENZYMES INCREASED & 7 & Liver and biliary system disorders- & $7(4.2)$ \\
\hline HYPERGLYCAEMIA & 1 & Metabolic and nutritional disorders & $3(1.8)$ \\
\hline OEDEMA DEPENDENT & 1 & & \\
\hline WEIGHT INCREASE & 1 & & \\
\hline ARRHYTHMIA & 1 & Heart rate and rhythm disorders & $1(0.6)$ \\
\hline DYSPNEA & 2 & Respiratory system disorders & $2(1.2)$ \\
\hline DYSURIA & 1 & Urinary system disorders & $1(0.6)$ \\
\hline HEADACHE & 10 & Body as a whole - general disorders & $20(12.3)$ \\
\hline TEMPERATURE CHANGED & 4 & & \\
\hline \multicolumn{4}{|l|}{ SENSATION } \\
\hline CHEST PAIN & 2 & & \\
\hline FEVER & 2 & & \\
\hline ASTHENIA & 1 & & \\
\hline OEDEMA PERIORBITAL & 1 & & \\
\hline APPLICATION SITE REACTION & 3 & Application site disorders & $3(1.8)$ \\
\hline
\end{tabular}

* System-Organ Classes 
두통(10건, $6.1 \%)$ 이 그 뒤를 이었다. 약물유해반응 의 빈도를 $\mathrm{SOC}$ 별로 살펴보면, 위장관계 장애가 68 건(41.5\%)으로 가장 많았고, 피부와 부속기관 장애 가 42 건(25.8\%)이었으며 이 두 종류의 SOC가 110 건으로 전체의 $67.5 \%$ 를 차지했다(Table 4 ).

\section{5) 약물병용상황}

약물유해반응의 의심약물로 지목된 한약만을 단 독으로 복용하고 있던 경우가 $51.5 \%$, 다른 약물을 병용하고 있던 경우가 $48.5 \%$ 였다. 약물을 병용한 사례 중에는 양약을 병용한 경우가 $27 \%$, 한약과 양
약을 모두 병용하고 있던 경우가 $12.3 \%$, 의심약물 외에 다른 한약을 병용한 경우가 $9.2 \%$ 였다(Table 5 ).

\section{6) 의심약물의 종류}

$$
\text { (1) 외용약 }
$$

외용약에 의한 약물유해반응으로 봉독 1건, 한방 파스 2건을 포함하여 총 3 건(1.8\%)이 보고되었다.

이들은 모두 30 세 이상 여성에서 적용부위에 발 생한 경도 유해반응이었다.

(2) 제제

Table 5. Status of Concomitant Drug Administration.

\begin{tabular}{cccc}
\hline Single administration (\%) & \multicolumn{3}{c}{ Concomitant administration (\%) } \\
\hline & & $79(48.5)$ & HD+WD \\
\cline { 2 - 4 } $84(51.5)$ & $\mathrm{HD}^{*}$ & $\mathrm{WD}^{\dagger}$ & $20(12.3)$ \\
\hline
\end{tabular}

* Herbal drug, †Western drug

Table 6. Demographic Data from the ADR*s associated with Manufactured Herbal Drug.

\begin{tabular}{cccc}
\hline & Total (\%) & Male (\%) & Female $(\%)$ \\
\hline Number & $36(100.0)$ & $11(30.6)$ & $25(69.4)$ \\
Age & $45 \pm 19.8$ & $44 \pm 25.1$ & $47 \pm 17.3$ \\
\hline
\end{tabular}

* Adverse drug reactions

Table 7. Numbers of Clinical Manifestations of ADR*s Due to Manufactured Herbal Drug.

\begin{tabular}{|c|c|c|c|}
\hline Clinical Manifestations & Number & $\mathrm{SOC}^{\dagger}$ & Number (\%) \\
\hline PRURITUS & 3 & Skin and appendages disorders & $6(16.7)$ \\
\hline SWEATING INCREASED & 1 & & \\
\hline RASH FOLLICULAR & 2 & & \\
\hline DIZZINESS & 3 & Central \& peripheral nervous system disorders & $5(13.9)$ \\
\hline HEADACHE & 2 & & \\
\hline PALPITATION & 3 & Autonomic nervous system disorders & $3(8.3)$ \\
\hline VOMITING & 2 & Gastro-intestinal system disorders & $17(47.2)$ \\
\hline DIARRHEA & 6 & & \\
\hline DYSPEPSIA & 4 & & \\
\hline ABDOMINAL PAIN & 4 & & \\
\hline NAUSEA & 1 & & \\
\hline HEPATIC ENZYMES INCREASED & 2 & Liver and biliary system disorders- & $2(5.6)$ \\
\hline TEMPERATURE CHANGED SENSATION & 1 & Body as a whole - general disorders & $3(8.3)$ \\
\hline CHEST PAIN & 1 & & \\
\hline OEDEMA PERIORBITAL & 1 & & \\
\hline
\end{tabular}

* Adverse drug reactions, ${ }^{\dagger}$ System-Organ Classes 
총 36 건(22.1\%)에서 17 종의 한약 제제가 의심약 물로 지목되었다. 제제에 의한 약물유해반응은 남성 (30.6\%)보다 여성 $(69.4 \%)$ 에서 더 자주 보고되었고, 대상 환자의 연령은 13 세에서 79 세 사이에 분포했 으며 평균연령은 $45 \pm 19.8$ 세였다(Table 6). 의심약물 로 지목된 한약만을 단독 복용한 경우는 17 건 (47.2\%)이었으며, 다른 약물을 병용한 경우는 19건 $(52.8 \%)$ 이었다. 보고된 약물유해반응의 중증도는 간 효소가 증가한 2 건을 제외하면 모두 경증이었다. 이 2 건의 사례는 사실 항고혈압제를 복용 중이던 1 명 의 환자(50대 여성)에서 1 회 발생한 유해사례로, 2 종의 한약제제(보로 $4 \mathrm{~g}$ bid pc, 태음인청심연자탕 $5 \mathrm{~g}$ tid pc)가 연달아 투약되던 중 유해사례가 발생하 였으므로 2건으로 계산된 것이다. 가장 자주 등장한 약물유해반응은 6건 발생한 설사였고, 복통이 34건, 그 다음은 각각 3 건씩으로 어지러움, 가려움증과 두 근거림이 그 뒤를 이었다(Table7). 약물유해반응을 $\mathrm{SOC}$ 로 구분했을 때, 가장 자주 등장한 $\mathrm{SOC}$ 는 위장 관계장애(17건, 47.2\%)였으며, 피부와 부속기관 장 애와 중추와 말초신경계장애가 각각 6건(16.7\%)과 5 건(13.9\%)이었다(Table 7). 하나의 SOC에 같은 약 물이 2회 이상 보고된 경우는 소청룡탕에서 피부와 부속기관 장애가 있었고, 삼출건비탕, 가미서경환, 소도환, 방풍통성산, 이기환에서 위장관계 장애를 일으킨 사례가 보고되었다(Table 8). 하나의 약물유 해반응에 같은 제제 약물이 반복 보고된 경우로는 이기환-설사(2건)의 조합 1 건 뿐 이었다.

\section{(3) 탕제}

전체 약물유해반응 163 건 중 124 건(76.1\%)이 탕 제에 의한 약물유해반응이었으며, 여기에는 66 종의 탕제가 포함되었다. 탕제에 의한 약물유해반응은 남 성보다 여성 $(68.5 \%)$ 에서 더 많았고, 여성의 평균연 령 $(54 \pm 18.5$ 세 $)$ 이 남성 $(40 \pm 23.8$ 세 $)$ 보다 더 높았다 (Table 9). 의심약물로 지목된 탕제만을 단독 복용한 경우는 65 건(52.4\%)이었으며, 기타 약물을 병용한 경우는 59건(47.6\%) 이였다. 귀비탕 복용 후 중증도 의 발진과 가려움증이 발생한 사례를 제외한 122 건
은 모두 경증 유해반응이었다. 가장 자주 등장한 약 물유해반응은 설사(23건)였고, 소화불량(16건)과 가 려움증(14건), 발진(12건)에 이어 두드러기(8건)와 두통(8건) 순으로 많이 보고되었다(Table 10). SOC 중에는 위장관계 장애가 51건(41.1\%)으로 가장 많 았고, 피부와 부속기관 장애는 36 건(29.0\%)이었다. 하나의 $\mathrm{SOC}$ 에 같은 약물이 2회 이상 보고된 경우 는 피부와 부속기관 장애에 가미보아탕, 가미삼황 탕, 가미원탕, 가미청열탕, 고삼호마산, 귀비탕, 당귀 수산, 생화탕, 자감초탕, 청심연자탕, 향사육군자탕 등이었고, 위장관계 장애를 일으킨 것은 가미원탕, 가미보아탕, 가미원탕, 방풍통성산, 보양환오탕, 보 중익기탕, 시호소간탕, 엄씨통규탕, 청심연자탕, 청 혈강기탕 등이었으며(Table 8), 하나의 약물유해반 응에 같은 탕제 약물이 2회 이상 보고된 경우는 가 미보아탕-구토(2건)의 단 1 개 조합 뿐이었다.

(4) 탕제 내 한약재

약물유해반응을 일으킨 탕제 중 특정 약재를 의 심약물로 지목할 수 있었던 사례는 6건의 보고서를 통하여 확인되었다. 지목된 한약재는 총 9종이었고, 15 건의 약물-유해사례 조합이 생성되었는데 이는 각 각 구기자-구토, 신이-구토, 신이-설사, 계지-설사, 모려분-설사, 황기-설사, 마황-불면, 모과-가려움증, 모과-두드러기, 모과-설사, 모과-속쓰림, 오미자-가려 움증, 오미자-혈당증가, 녹각교-가려움증, 녹각교-혈 당증가였다. 이를 SOC별로 구분했을 때 하나의 $\mathrm{SOC}$ 에 동일한 약재가 2회 이상 등장한 경우는 신 이(辛荑, Magnoliae Flos)로 신이-구토, 신이-설사와 같은 위장관계 장애가 각 1 회씩 보고되었다.

\section{고찰 및 제언}

약물유해반응은 독성학적, 약리학적으로 일부 예 측 가능하지만, 특이체질반응이나 과민반응, 알러지 반응, 약물의 중장기 독성 효과 및 약물 오남용에 의한 유해반응 등은 미리 탐지하기 어려우므로 시판 후 약물감시제도가 필요하다 ${ }^{18)}$. 약물감시의 결과 시 
Table 8. Repeated Occurrence of the ADR*s with the Same Drug - SOC Pairs.

\begin{tabular}{|c|c|c|c|}
\hline $\begin{array}{l}\text { Drug } \\
\text { Type }\end{array}$ & Drug & Clinical Manifestation & $\mathrm{SOC}^{\dagger}$ \\
\hline $\mathrm{HD}^{\ddagger}$ & Gamiboa-tang4 (加味補兒湯4) & PRURITUS, RASH & \multirow{14}{*}{$\begin{array}{l}\text { Skin and appendages } \\
\text { disorders }\end{array}$} \\
\hline $\mathrm{HD}$ & Gamisamhwang-tang1 (加味三黃湯1) & PRURITUS, URTICARIA, RASH & \\
\hline $\mathrm{HD}$ & Gamiwon-tang2 (加味元湯2) & PRURITUS, URTICARIA & \\
\hline $\mathrm{HD}$ & Gamicheongyeol-tang1 (加味淸熱湯1) & PRURITUS, RASH & \\
\hline $\mathrm{HD}$ & Gosamhoma-san 1 (苦蓼胡麻散1) & PRURITUS, URTICARIA & \\
\hline $\mathrm{HD}$ & Gwibi-tang1 (歸脾湯1) & PRURITUS, RASH & \\
\hline $\mathrm{HD}$ & Gwibi-tang3 (歸脾湯3) & PRURITUS, RASH & \\
\hline $\mathrm{HD}$ & Danggwisu-san1 (當歸䰅散1) & PRURITUS, RASH & \\
\hline $\mathrm{HD}$ & Saenghwa-tang2 (生化湯2) & PRURITUS, URTICARIA, RASH & \\
\hline $\mathrm{HD}$ & Untitled decoction2 (任意處方2) & PRURITUS, RASH & \\
\hline $\mathrm{HD}$ & Jagamcho-tang1 (多甘草湯1) & PRURITUS, URTICARIA, RASH & \\
\hline $\mathrm{HD}$ & Cheongsimyeonja-tang2 (清心蓮子湯2) & URTICARIA, RASH & \\
\hline $\mathrm{HD}$ & Hyangsayuggunja-tang1 (香砂六君子湯1) & PRURITUS, URTICARIA & \\
\hline $\mathrm{MHD}^{\S}$ & Socheonglyong-tang (小靑龍湯) & PRURITUS, RASH FOLLICULAR & \\
\hline MHD & Samchulgeonbi-tang (蔘术健脾湯) & DIARRHEA, DYSPEPSIA & \multirow{17}{*}{$\begin{array}{l}\text { Gastro-intestinal system } \\
\text { disorders }\end{array}$} \\
\hline MHD & Gamiseogyeong-hwan (加味舒經丸) & ABDOMINAL PAIN, DYSPEPSIA & \\
\hline MHD & Sodo-hwan (消導丸) & $\begin{array}{l}\text { ABDOMINAL PAIN, DIARRHEA, } \\
\text { DYSPEPSIA }\end{array}$ & \\
\hline MHD & Bangpungtongseong-san (防風通聖散) & ABDOMINAL PAIN, DIARRHEA & \\
\hline MHD & Igi-hwan (理氣丸) & $\begin{array}{l}\text { ABDOMINAL PAIN, DIARRHEA, } \\
\text { DIARRHEA" }\end{array}$ & \\
\hline $\mathrm{HD}$ & Gamiwon-tang1 (加味元湯1) & ABDOMINAL PAIN, DIARRHEA & \\
\hline $\mathrm{HD}$ & Gamiboa-tang2 (加味補兒湯2) & DYSPEPSIA, FLATULENCE & \\
\hline $\mathrm{HD}$ & Gamiboa-tang5 (加味補兒湯5) & VOMITING, VOMITING" & \\
\hline $\mathrm{HD}$ & Gamiwon-tang2 (加味元湯2) & DIARRHEA, DYSPEPSIA & \\
\hline $\mathrm{HD}$ & Bangpungtongseong-san2 (防風通聖散2) & DIARRHEA, DYSPEPSIA & \\
\hline $\mathrm{HD}$ & Boyanghwano-tang1 (補陽還五湯1) & ABDOMINAL PAIN, DIARRHEA & \\
\hline $\mathrm{HD}$ & Bojungiggi-tang3 (補中益氣湯3) & DIARRHEA, DYSPEPSIA & \\
\hline $\mathrm{HD}$ & Sihosogan-tang1 (柴胡疎肝湯1) & VOMITING, DYSPEPSIA & \\
\hline $\mathrm{HD}$ & Eom's tonggyu-bang1 (嚴氏通憿方 1 ) & DIARRHEA, DYSPEPSIA & \\
\hline $\mathrm{HD}$ & Untitled decoction6 (任意處方6) & DIARRHEA, DYSPEPSIA & \\
\hline $\mathrm{HD}$ & Cheongsimyeonja-tang (淸心蓮子湯1) & DIARRHEA, FLATULENCE & \\
\hline $\mathrm{HD}$ & $\begin{array}{l}\text { Taeeumincheonghyeolganggi-tang1 } \\
\text { (太陰人淸血降氣湯1) }\end{array}$ & ABDOMINAL PAIN, DYSPEPSIA & \\
\hline
\end{tabular}

판되어 잘 사용되던 약물도 미처 예측하지 못한 유 해반응을 뒤늦게 발견하여 시장에서 회수되는 경우 도 있다 ${ }^{19)}$. 시판후 약물감시제도의 대표적인 수단 중 하나가 자발적부작용보고제도이다 ${ }^{10)}$.

한약은 일반적으로 합성의약품에 비해 약리학적,
독성학적 특성이 잘 알려져 있지 않으므로 약물유해 반응을 파악하기 위해서는 약물감시활동이 더욱 중 요하다고 할 수 있다 ${ }^{18)}$. 그러나 한국에서 한약은 사 실상 약물감시제도의 사각지대에 놓여있다. 2012년 4 월 한국의약품안전관리원이 생기면서 식약처의 품 
Table 9. Demographic Data from the ADR*s associated with Herbal Decoction.

\begin{tabular}{cccc}
\hline & Total (\%) & Male (\%) & Female (\%) \\
\hline Number & $124(100.0)$ & $39(31.5)$ & $85(68.5)$ \\
Age & $50 \pm 21.3$ & $40 \pm 23.8$ & $54 \pm 18.5$ \\
\hline
\end{tabular}

*Adverse drug reactions

Table 10. Numbers of Clinical Manifestations of ADR*s Due to Herbal Decoction.

\begin{tabular}{|c|c|c|c|}
\hline Clinical Manifestations & Number & $\mathrm{SOC}^{\dagger}$ & Number (\%) \\
\hline PRURITUS & 14 & Skin and appendages disorders & $36(29.0)$ \\
\hline RASH & 12 & & \\
\hline URTICARIA & 8 & & \\
\hline SWEATING INCREASED & 1 & & \\
\hline ACNE & 1 & & \\
\hline MYALGIA & 1 & Musculo-skeletal system disorders & $1(0.8)$ \\
\hline DIZZINESS & 2 & Central \& peripheral nervous system disorders & $3(2.4)$ \\
\hline HYPERTONIA & 1 & & \\
\hline PALPITATION & 3 & Autonomic nervous system disorders & $3(2.4)$ \\
\hline INSOMNIA & 3 & Psychiatric disorders & $3(2.4)$ \\
\hline DIARRHEA & 23 & Gastro-intestinal system disorders & $51(41.1)$ \\
\hline DYSPEPSIA & 16 & & \\
\hline ABDOMINAL PAIN & 6 & & \\
\hline VOMITING & 3 & & \\
\hline FLATULENCE & 2 & & \\
\hline NAUSEA & 1 & & \\
\hline HEPATIC ENZYMES INCREASED & 5 & Liver and biliary system disorders- & $5(4.0)$ \\
\hline HYPERGLYCAEMIA & 1 & Metabolic and nutritional disorders & $3(2.4)$ \\
\hline OEDEMA DEPENDENT & 1 & & \\
\hline WEIGHT INCREASE & 1 & & \\
\hline ARRHYTHMIA & 1 & Heart rate and rhythm disorders & $1(0.8)$ \\
\hline DYSPNEA & 2 & Respiratory system disorders & $2(1.6)$ \\
\hline DYSURIA & 1 & Urinary system disorders & $1(0.8)$ \\
\hline HEADACHE & 8 & Body as a whole - general disorders & $15(12.1)$ \\
\hline TEMPERATURE CHANGED SENSATION & 3 & & \\
\hline FEVER & 2 & & \\
\hline ASTHENIA & 1 & & \\
\hline CHEST PAIN & 1 & & \\
\hline
\end{tabular}

*Adverse drug reactions , , ${ }^{\dagger}$ System-Organ Classes

목허가를 받은 한약제제의 경우에는 의약품으로 분 류되어 의약품유해사례보고시스템(KAERS)으로 보 고할 수 있게 되었으나 아직 모든 한약제제가 등록 되어 있는 것은 아니며, 정작 한의 임상에서 주로 사용되는 탕제나 한약제는 이 시스템에서도 보고할 수 없다 ${ }^{20)}$.

2008년부터 2012년 2월까지 동국대학교 한방병 원 $\mathrm{EMR}$ 에 연계된 자발적 약물부작용보고 시스템에 기반하여 한약의 약물유해반응에 대해 보고한 권 등
11)의 연구는 약물감시 측면에서 한약의 안전성을 다 룬 국내 첫 시도였다. 권 등은 한약이 의심약물로 지목된 28건의 부작용 보고서에서 총 39건의 약물 유해반응을 확인하였다. 그러나 당시에는 시스템을 구축하기는 하였으나 체계적 관리가 미흡하여 보고 건수가 적었으며, 연구자 단독으로 인과성 평가를 수행하여 연구의 객관성을 확보하는데 부족한 측면 이 있었다. 이에 저자들은 권 등의 선행연구 이후 2012년 4월부터 2014년 12월까지 같은 시스템에 축 
적된 부작용 보고서를 새롭게 확보하여 101 건의 보 고서에서 163 건의 약물유해반응을 확인하였다.

부작용을 신고한 보고자를 직군별로 분류해보면 간호사가 가장 많았다. 이는 간호사의 보고율이 $92 \%$ 로 가장 높았다는 김 등의 보고와 일치한다 ${ }^{21)}$. 하지만 권 등의 선행연구에서는 한의사에 의한 보고 가 15 건으로 가장 많았고, 간호사는 5건으로 가장 적었다. 시스템 구축 초기에는 보고율이 워낙 낮아 그와 같은 결과를 낳은 것으로 생각되며, 간호사의 경우 약물부작용보고에 대해 지속적으로 교육하고 신고를 적극 독려한 결과 성과를 거둔 것으로 보고 율 제고를 위해서는 지속적인 교육과 환기가 필수적 임을 알 수 있다.

원내 센터의 평가진이 작성한 보고서를 연구자가 재검토하여, 보고서의 주요 내용을 수정하거나 인과 성평가 결과를 변경한 사례가 일부 있었는데, 이는 작성자 및 평가자의 개인차에서 발생한 문제라기 보 다는 센터 평가진이 의사와 약사, 연구간호사로만 구성되어 있어서 발생한 문제이다. 한의학 용어나 탕제 조제 때문에 발생하는 탕제 처방과 복용 시점 간의 시간차 등 한의 진료의 특성에 대한 이해가 부 족하다 보니 의심약물이나 부작용이 잘못 선택되기 도 하고, 인과성 평가 결과가 달라지기도 했다. 이는 한약에 의한 약물유해반응을 검토하고 정확히 평가 하려면 한의 임상 실제를 잘 알고 있는 한의사나 한 약사의 참여가 중요하다는 것을 실증적으로 보여주 는 것이다.

인과성평가의 보조도구로 사용한 $\mathrm{KA}$ 는 인과성평 가를 위해 8 개 항목에 대해 점수를 부여하는데, 8 개 항목 중 확보 가능한 정보가 약물 처방과 부작용 발 생의 시간적 선후관계를 제외하고는 부족한 경우가 태반이었다. 이는 약물 투약 전후에 필요한 검사가 제한되어 있어 기본적인 혈액 검사나 소변검사조차 자유롭게 시행하기 어려운 제도적 한계가 주요한 원 인이다. 그밖에 유사한 부작용 과거력이나 발생한 부작용에 대한 대처 방안, 감량 혹은 중단 후 반응, 재투약 여부 혹은 재투약 후 반응 등 부작용과 관련 된 주요 정보를 의무기록에 충실히 기재해야 확보되
는 것이다.

이외에도 허가사항 등에 반영된 약물에 대해 알 려진 정보에 대한 근거 구축이 필요하다. $\mathrm{KA}$ 를 적 용한 177 건 중 이 항목에 대한 정보가 제공된 경우 는 한방파스 2 건과 봉독 1 건(투여부위 장애), 마황 1 건(불면)이 전부였다. 기존의 약리학적, 독성학적 연 구 외에도 제한적이지만 이미 문헌에 보고된 한약의 안전성에 대한 근거 중 적절한 것들을 취합하고, 이 번 연구처럼 약물감시체계에서 얻은 임상 정보를 바 탕으로 한약의 안전성에 대한 $\mathrm{DB}$ 를 구축해야 한다.

이 연구를 통해 확보한 163 건의 한약약물유해반 응을 살펴보면, 약물유해반응의 종류로 가장 많은 것은 위장관계 장애였고, 그 다음이 피부와 부속기 관 장애였으며, 이 둘을 합치면 전체의 $67.5 \%$ 에 달 하였다. 이는 선행연구 뿐만 아니라, 식약청에 보고 된 일반적인 약물유해반응 자료를 분석한 유 등 22$)$ 의 연구 결과와도 일치하여, 한약에 의한 약물유해반응 유형이 일반적인 합성의약품과 크게 다르지 않다는 사실을 반영한다.

한약에 의한 약물유해반응이 발생한 대상 환자의 연령 성별 분포 역시, 선행연구와 마찬가지로 여성 과 50 대 고령층에서 높아, 여성과 노인이 약물유해 반응에 취약한 것으로 알려져 있는 일반적인 사실과 부합하였다 ${ }^{21,22)}$. 하지만 연구기간 동안 해당 의료 기관에서 한약을 처방 받은 전체 인구집단의 특성을 알지 못하고, 40-50대 중장년층과 여성의 이용비율 이 높은 한방의료 이용실태를 고려하면 이들 계층이 한약약물유해반응에 취약하다고 확언할 수는 없다 23).

보고된 한약약물유해반응의 중증도는 159 건 (97.5\%)이 경증(mild)이었고, 중등증(moderate)은 4 건(2.5\%)에 불과했는데, 중등증으로 분류된 사례는 간효소증가 혹은 발진 및 가려움증으로 응급실 진료 를 받게 되었지만 약물 중단후 반응을 알 수 없어 인과관계가 possible로 판정된 성인 여성의 사례였 다. 보고된 사례 중 중증(severe)은 없었다. 이는 권 등의 선행연구 ${ }^{11)}$ 에서 중증 유해반응은 없었고, $10 \%$ 의 중등증 외에는 모두가 경증 반응이었던 것과 유 
사한 결과이다.

이 연구는 자발적부작용보고체계에 기반하였다는 점에서 과소보고(under-reporting)라는 한계를 벗어 나기 어렵다 ${ }^{18)}$. 즉, 이 시스템이 연구 기간 동안 본 원에서 발생한 한약약물유해반응 전체를 빠짐없이 반영했다고 할 수 없다. 이 연구에 포함된 보고건 중에 외용약의 비율이 극히 낮았는데(한방파스2건, 봉독1건 - 적용부위장애), 실제로 비경구약물이 안 전하기 때문이라기보다는 이 역시 과소보고 때문일 가능성이 높다. 또한 약물병용상황은, 원내 처방전 및 의무기록에만 의존하여 확인했기 때문에 실제 약 물 병용상황을 모두 반영했다고 보기는 어렵다.

한약의 평가단위를 어떻게 할 것 인가도 해결해 야 할 문제이다. WHO-UMC에서는 한약약물유해반 응을 평가할 때 원인약물을 한약재 별로 분류하지 만, 우리나라의 경우 단미 한약재보다는 여러 한약 재가 복합된 탕제를 많이 복용하고 있고, 동일한 한 약재라도 상이한 기원식물을 사용하는 경우도 있으 며, 특정 처방집에 근거하지 않고 구성 약재를 자가 조제한 탕제를 많이 사용하고 있기 때문에 의심약물 을 개별 한약재로 분리 식별하여 보고하는 것은 매 우 번거롭고 어려운 방법일 수 있다 ${ }^{18)}$.

이 연구에서는 한약을 포장단위로 평가했다. 그 결과, 같은 약물에 대해 동일한 유해반응이 2회 이 상 반복 보고된 경우는 매우 드물었다. 원내 제조 환제인 이기환이 설사를 유발한 2례와, 가미보아탕 가감방이 소아에서 구토를 유발한 2례가 전부였다. 탕제의 경우, 예외적으로 유해반응 발생 전후로 구 성 약재 중 일부 약재의 용량 변동이 확인되어 특정 약재를 의심약물로 지목할 수 있었던 소수의 사례가 있었는데, 그 중 가미보아탕가감방에 포함된 신이 (辛荑)가 소아 환자에서 각각 설사와 구토, 공통적으 로 위장관계 부작용을 유발하였다. 변비 조절을 위 해 투약한 이기환이 설사를 반복 유발한 사례는 예 측 가능한 반응이지만 의도한 것보다 반응 정도가 더 심하게 발생한 사례이고, 신이(辛荑)를 포함하거 나 혹은 포함하지 않은 가미보아탕가감방은 소아에 서 설사, 구토 등 위장관계 부작용을 반복 발생시켰
다. 하지만 이들 사례는 모두 단 2회 반복 탐지 되었 을 뿐이고, 의심약물로 지목된 한약 외에도 다른 요 인에 의해서도 유해사례가 발생했을 가능성을 배제 할 수 없으며, 투약 중단 후 반응을 확인할 수 없어 서 모두 그 인과관계가 possible로 판정된 예이다. 따라서 보고된 약물유해반응이 이들 반복 지목된 제 제, 탕제, 혹은 탕제 내의 특정 한약재라고 확언하기 에는 어려움이 있다

이 연구에서는 권 등의 선행연구11) 보다 좀 더 많 은 수의 약물유해반응 사례를 확보하여 한방의료기 관의 부작용보고양상 및 한약에 의한 약물유해반응 의 현황을 좀 더 명확하게 파악할 수 있었다. 하지 만 특정 약물과 특정 유해반응 간의 강력한 인과관 계에 대한 근거는 확보하지 못했는데, 이는 심각한 약물유해반응이 한 건도 발생하지 않았으며, 특정 약물과 특정 사례간의 조합이 반복 탐지되지 않았기 때문이다. 이를 근거로 역시 한약은 안전하다는 하 나의 근거가 도출된 것으로 판단하는 것은 적절하지 않다. 물론 한약의 약물유해반응이 매우 드물게 나 타나는 것을 확인한 것은 맞지만 약물감시는 그 드 문 부작용을 찾고자 하는 것이다. 즉, 한 두 개의 한 방병원만으로는 약물감시를 하더라도 드물게 발생 하는 한약의 약물유해반응을 탐지하고 관리하기 어 렵기 때문에 훨씬 더 대규모의 약물감시체계가 필요 하다고 주장 하는 것이다.

현재 탕제는 부작용이 발생하여도 그 사례를 보 고할 수 있는 체계가 갖추어져 있지 않고, 한약제제 의 경우 의약품으로 분류되어 보고를 받고 있기는 하나 매우 제한적이며 보고 건수도 희소하다. 실제 임상에서 한약제제보다 탕제가 더 많이 쓰이고 있는 실정을 고려하면, 탕제도 약물감시체계 안에 포함시 켜야 한다. 한약제제와 탕제가 모두 한방의료기관에 서 한약으로 통용되고 있는 현실을 고려할 때, 이 둘을 분리하기보다는 통합하여 한의약의 전문가인 한의약계에서 관리하도록 하는 것이 적절하다.

이를 위해서 식품의약품안전처와 한국의약품안전 관리원에서는 중앙의약품안전센터에 대한한의사협 회를 추가하여야 한다. 한의사협회 중앙회가 중앙센 
터가 되고 전국의 시도지부 한의사회와 연계하여 지 역 한방병의원에서 약물감시를 하도록 하여야 한다. 또한 기존의 25 개의 지역의약품안전센터에 한약에 대한 보고체계를 추가하여 구축하도록 하여야 하며, 지역센터_중에 일부는 한방병원도 추가해야 한다. 또한 한방의료기관 종사자를 대상으로 약물감시체 계와 한약부작용 신고의 중요성과 의미를 적극적으 로 교육 홍보하여야 하며, 부작용사례를 수집하고 인과성 평가를 수행할 수 있는 전문가를 양성하고, 전문가 양성 시스템을 구축해야 한다.

한약에 대한 전국 규모의 자발적 약물부작용보고 시스템을 구축하여 한약의 안전성에 관한 양질의 데 이터를 축적하고, 수집된 정보를 한약관련 약물감시 제도 전문가가 평가하여 과학적 근거가 있는 자료를 산출해야 비로소 소비자가 수긍하고 한약의 안전성 에 대한 신뢰를 회복할 수 있을 것이다. 이러한 작 업은 다른 누구도 아닌, 한의계가 정부에 요구하고 자발적으로 나서서 수행하여야 한다.

이 연구는 다음과 같은 한계를 가지고 있다. 이 연구 결과가 우리나라 전체 한약약물유해반응의 특 성을 대표한다고 확신할 수 없다. 또한 원내에서 발 생한 약물유해반응 전수를 포괄하지도 못한다. 이 연구의 자원은 한 한방의료기관의 원내 $\mathrm{EMR}$ 의 자 발적 약물부작용 보고 시스템에 보고된 사례만을 대 상으로 하였기 때문이다. 이 자료는 통계학적으로 엄밀하게 표본 추출하여 얻은 결과가 아니며, 따라 서 이 연구 결과에 지나친 통계적 의미를 부여하거 나, 우리의 결과를 한약약물유해반응의 일반적 특성 으로 확대해석 하는 데는 주의하여야 한다.

\section{감사의 글}

이 연구는 보건복지부 한의약선도기술개발사업에 서 지원하는 '한약에 의한 약물유해반응 관찰을 위 한 전향적 코호트 구축(HI13C0656)' 과제를 통해 수행되었다.

\section{참고문헌}

1. Cheon C, Park JS, Park S, Kweon KT, Shin Y, Ko SG. Necessity of Adverse Event Reporting System through the Trend of Internet News about Safety of Herbal Medicine. Kor. J. Oriental Preventive Medical Society. 2011;15(2):131-43.

2. Jang IS, Yang CS, Lee SD, Han CH. A Review of Herbal Medicinal Products Associated with Toxic Events in Korea. J Korean Oriental Med. 2007;28(1):1-10.

3. Heinrich M, Chan J, Wanke S, Neinhuis C, Simmonds MS. Local uses of Aristolochia species and content of nephrotoxic aristolochic acid 1 and 2--a global assessment based on bibliographic sources. Journal of ethnopharmacology, 2009;125(1):108-44.

4. Haller CA, Benowitz NL. Adverse Cardiovascular and Central Nervous System Events Associated with Dietary Supplements Containing Ephedra Alkaloids. New England Journal of Medicine. 2000;343(25):1833-8.

5. Sato A, Toyoshima M, Kondo A, Ohta K, Sato $\mathrm{H}$, Ohsumi A. [Pneumonitis induced by the herbal medicine Sho-saiko-to in Japan]. Nihon Kyobu Shikkan Gakkai zasshi. 1997;35(4):391-5.

6. Suk KT, Kim DJ, Kim CH, Park SH, Yoon JH, Kim YS, et al. A Prospective Nationwide Study of Drug-Induced Liver Injury in Korea. Am J Gastroenterol. 2012;107(9):1380-7.

7. Lee J, Son C, Lee JA, Choi J, Lee MS. Do herbal medicines negatively affect liver tests? A systematic review of Korean clinical studies on safety. European Journal of Integrative Medicine. 2014;6(4):441-50.

8. Shin HK, Jeong SJ, Lee MS, Ernst E. Adverse events attributed to traditional Korean medical practices: 1999-2010. Bull World Health Organ. 2013;91(8):569-75.

9. Korea Institute of Drug Safety \& Risk Management. 
Pharmacovigilance. 2014. Available at: URL:https: //www.drugsafe.or.kr/iwt/ds/ko/information/ EgovDrugWatchTerm.do. Accessed February 21, 2014.

10. Korean Society for Pharmacoepidemiology \& Risk Management. Pharmacoepidemiology. 2 ed. SNU Book. 2012:1-9, 33, 74-82, 108-121.

11. Kwon YJ, Cho WK, Han CH. Status of Herbal-drug-associated Adverse Drug Reactions Voluntarily Reported by EMR. J. Int. Korean Med. 2012;33(4):485-97.

12. Korea Institute of Drug Safety \& Risk Management. Adverse Drug Reaction Assessment Report. 1 ed. Korea Institute of Drug Safety \& Risk Management. 2013:60-63.

13. Herbology Textbook Compilation Commitee for College of Korean Medicine, Herbology. Yeonglim. 2011.

14. WHO. WHO Monographs on Selected Medicinal Plants. WHO 2009.

15. Ryu JH. Analysis of Spontaneously Reported Adverse Drug Reactions(ADRs) and a Survey Regarding ADR from a Single Hospital. Chungnam National University. 2013.

16. Kyung EJ, Ryu JH, Kim EY. Evaluation of adverse reactions to contrast media in the hospital. 2013;86(1032):20130418.

17. Korea Institute of Drug Safety \& Risk
Management. Terminology Guide for Reporting Adverse Drug Reactions. Korea Institute of Drug Safety \& Risk Management. 2014:1-6.

18. Shaw D, Graeme L, Pierre D, Elizabeth W, Kelvin C. Pharmacovigilance of herbal medicine. Journal of ethnopharmacology. 2012;140(3): 513-8.

19. Park JW. Spontaneous Adverse Drug Reaction Reporting Program in Korea JPERM. 2008; 1:20-4.

20. Woo YJ, Chung SY, Park BJ. Current Status of Spontaneous Adverse Reactions Reporting System on Herbal Medicine in China, Japan, Korea and WHO. J. Int. Korean Med. 2014; 35(2):111-8.

21. Kim MG, Kang HR, Kim JH, Ju YS, Park SH, Hwang YI, et al. Analysis of adverse drug reactions collected by an electronic reporting system in a single hospital. The Korean Journal of Medicine. 2009;77(5):601-9.

22. Rhew KY, Lee S. Analysis of the Korea Food and Drug Administration Adverse Drug Reaction Reports. Kor. J. Clin. Pharm. 2011;21(2):138-44.

23. Korean Institute for Health \& Social Affairs. The Domestic Survey on the Usage and Awareness Level of Korean Medicine. Health \& Welfare Issue \& Focus. 2012;140(2012-21):1-8. 